\title{
Model Pembelajaran Hybrid Learning pada Mata Kuliah Sepakbola di Pendidikan Olahraga FKIP UMS
}

\author{
Pungki Indarto*a, Muhad Fatoni ${ }^{b}$, Nurhidayat ${ }^{c}$ \\ ${ }^{a b c}$ Universitas Muhammadiyah Surakarta, Jl A. Yani Tromol Pos 1 Pabelan Kartasura Surakarta 57162, Indonesia
}

*corresponding author mail: pi311@ums.ac.id

\section{A R T I CLE INFO}

\section{Article history:}

Received 22 October 2018

Received in revised form 11

November 2018

Accepted 14 November 2018

Keywords:

learning model, hybrid learnig, soccer

\begin{abstract}
A B S T R A C T
1). The hybrid learning model is the process of learning which is the mixture of face to face and on line learning models. 2). Theadvancement of the learning result and the mastery of skills on the soccer lecture series in the faculty of education and teacher training of UMS. 3). The students enthusiasm in taking the lecture series using the hybrid learning in in the faculty of education and teacher training of UMS. The method of research applies the steps of Borg and Gall up to the seventh steps in small scale. Data is taken from the questionnaires and tests. Data analysis is inthe form of descriptive and the product effectively tests. From the result of the research, it can be concluded that Hybrid learning is suitable to be applied in the lecture series of soccer in the faculty of education and teacher training of UMS.The Hybrid learningmethod is able to increase the achievement of the students from the average score of 6.8 with the total score of 204before applying the method, and after applying the learning media the score increase to 7.53 with the total score of 225.8. There is a variance from the pretest and posttest as much as 0.73 point. So, it can be concluded that there is an increase in the use of hybrid learning in the soccer lecture seriesin the faculty of eduation and teacher training of UMS
\end{abstract}

\section{Pendahuluan}

Pendidikan Olahraga Fakultas Pendidikan Keguruan dan Ilmu Pendidikan Universitas Muhammadiyah Surakarta salah satu program studi yang mencetak sumber daya manusia dalam bidang keolahragaan. Seiring bertambahnya jumlah mahasiswa, akan bertambah jam mengajar pada tiap dosen sehingga waktu untuk bimbingan dan konsultasi semakain sedikit. Pembelajaran pada prodi olahraga masih menggunakan pendekatan yang berpusat pada pengajar (teacher centered).

Media belajar tidak variatif dan belum banyak dikembangkan. Penggunaan internet sebagai fasilitas kampus dirasa belum dapat dioptimalkan oleh mahasiswa dan dosen dalam aktifitas belajar mengajar. Strategi dosen dalam proses pembelajaran juga kurang efektif yaitu menjelaskan materi kembali secara langsung di dalam modul dilanjutkan tanya jawab kemudian memberikan tugas serta latihan yang ada di dalam modul. Hal ini yang perlu adanya perubahan strategi pembelajaran supaya proses pembelajaran menjadi efektif dan dapat mengikuti perkembangan arus informasi yang serba cepat. E-learning merupakan sebuah contoh penerapan pembelajaran yang mengikuti cepatnya arus informasi. E-learning sebagai terobosan media pembelajaran yang tidak hanya menggunakan pertemuan tatap muka, akan tetapi proses pembelajaran via jarak jauh lintas tempat dan waktu.

E-learning menurut learnFram.com dalam glossary of e-learning terms (glossary, 2001) " e elarning adalah sistem pendidikan yang menggunakan aplikasi elektronik untuk mendukung belajar mengajar dengan media internet, jaringan komputer, maupun komputer standalone." Jadi bisa disimpulkan e-learning merupakan merupakan cara baru dalam proses pembelajaran dengan media khusus internet 
dalam pembelajarannya, e-learning merupakan konsekuensi dari majunya teknologi informasi.

Definisi diatas dapat diartikan dalam menghadapi tantangan dunia pendidikan saat ini harus memerhatikan tingkat perkembangan media informasi dan teknologi supaya tidak tertinggal jauh dengan negara- negara maju yang terlebih dahulu mengenal teknologi. E-Learning hadir di kampus bukan berarti proses pembelajaran tatap muka (konvensional) lantas ditinggalkan, akan tetapi perpaduan antara kedua metode akan mempercepat penguasaan secara konsep dan penguasaan secara ketrampilan.

Sistem dan aplikasi e-learning juga disebut learning management system (LMS) adalah system perangkat lunak yang memvirtualisasi proses belajar mengajar konvensional guna administrasi, dokumentasi, laporan suatu program latihan, ruangan kelas, dan peristiwa online, program e-learning dan konten pelatihan (Ellis, 2009).

Pernyataan di atas memastikan bahwa peran e learning dalam aktifitas dosen mengajar dapat membentuk dan dapat mengefektifkan tercapainya tujuan pengajaran, interaksi dosen dan mahasiswa menjadi efektif. pertemuan tatap muka dengan penyampaian rencana kelas yang dapat di akses mahasiswa sebelum perkuliahan tatap muka dilaksanakan. Penggunaan model hybrid learning ini memerlukan need assessment yang berfungsi apakah metode e-learning dapat mendukung metode tatap muka (konvensional) di Pendidikan Olahraga Fakultas Pendidikan Keguruan dan Ilmu Pendidikan Universitas Muhammadiyah Surakarta.

Berdasarkan latar belakang di atas akan dikembangkan model pembelajaran hybrit learning, dengan harapan terbentuknya system pembelajaran berbasis informasi dan teknologi di Pendidikan Olahraga Fakultas Pendidikan Keguruan dan Ilmu Pendidikan Universitas Muhammadiyah Surakarta.

Tujuan penelitian hybrid learning ini yaitu, a) Model produk pembelajaran hybrid learning.
Model pembelajaran hybrid learning adalah gabungan pembelajaran tatap muka (konvensional) dengan pembelajaran e-learning yang diharapkan mahasiswa menguasai konsep materi maupun ketrampilan gerak dalam perkuliahan sepakbola, b) Peningkatan kemandirian dan keaktifan dalam mengikuti perkuliahan dengan memanfaatkan e-learning di Pendidikan Olahraga Fakultas Pendidikan Keguruan dan Ilmu Pendidikan Universitas Muhammadiyah Surakarta, c) Hasil belajar mahasiswa meningkat dengan adanya hybrid learning.

\section{Kajian Pustaka}

Internet dengan berbagai aplikasi dapat ditemukan sebagai media mempermudah mencari informasi dimanapun dan kapanpun. Dijelaskan Sibero (2011a:10) internet adalah komputer yang terhubung (Interconnected Network) dari beberapa jaringan secara global, dalam arti lain internet jaringan luas dan jaringan alam.”. internet mempunyai kesamaan dengan jaringan komputer area dalam penggunaan protocol komunikasi yaitu menggunakan TCP (Transmission Control Protocol) atau IP (Internet Protocol).

Kajian di atas sangat menarik apabila internet dimanfaatkan dalam pembelajaran (e learning).. Soekartawi (2002:56) kelebihan pembelajaran berbasis internet adalah : 1) tidak ada batasan waktu dan tempat dalam interaksi belajar dan mengajar antara guru dan murid. 2) materi dan petunjuk pembelajaran dapat disusun secara terstruktur dan terjadwal melalui internet. 3) bahan ajar dapat dilihat kapanpun dan dimanapun. 4) komunikasi dapat dilakukan lewat internet secara langsung apabila membutuhkan penjelasan atau informasi tambahan. 5) dapat melakukan diskusi secara klasikal. 6) siswa menjadi lebih aktif. 7) lebih efektif dan efisien secara waktu dan jarak. 8) LMS atau softwere yang dipakai dalam e leraning moodle, efront, atutor, schoology dan lain- lain.

Banyak kemudahan yang ditawarkan dari softwere ini selain mudah dalam manfaatnya 
softwere LMS ini bersifat terbuka dan bebas (open source atau freewer). Pemilihan softwere LMS yang tepat akan berpengaruh terhadap keberhasilan pembelajaran karena didalamnya terdapat fitur, kemudahan, dan kelengkapan kebutuhan dalam sebuah kelas. Pengguna Schoology untuk e learning lebih mempunyai kelengkapan fitur seperti multy courses, recent activity, group, grade, calender, resources dan lain lain yang memudahkan untuk mengelola puluhan ribu pengguna dalam akses yang tinggi.

\section{Metode Penelitian}

Pengembangan model hybrid learning pada mata kuliah sepakbola akan diterapkan pada program studi pendidikan olahraga fakultas keguruan dan ilmu pendidikan universitas muhammadiyah Surakarta (POR FKIP UMS) pelaksanaan hybrid learning ini dimaksudkan adanya variasi pendekatan atau metode pembelajaran yang sesuai dengan perkembangan era informasi dan telekomunikasi. Selain itu aktifitas mahasiswa lebih besar dalam memperoleh informasi, materi dan diskusi, penerapan e learning ini tidak begitu saja menghilangkan pembelajaran tatap muka, sehingga perlu dikembangkan model hybrid learning yaitu, pembelajaran yang memadukan pembelajaran menggunakan kelas media internet (modern) dan pembelajaran kelas dengan tatap muka (konvensional).

Langkah penelitian pengembangan model pembelajaran (Gall and Borg, 1979:626). 1) analisis situasi dengan mengumpulkan informasi yang diperlukan, 2) penyusun program pengembangan, 3) prototype produk awal (model hipotesis), 4) uji pengembangan produk awal, 5) revisi produk 1,6 ) uji produk 1,7 ) revisi produk 2 untuk menghasilkan produk utama, 8) uji lapangan operational, 9) revisi produk akhir produk, 10) penerapan produk akhir. Pengembangan ini hanya sampai langkah ke 7 karena penelitian ini berskala kecil.

\section{Langkah Penelitian}

Pengembangan model pembelajaran hybrid learning memiliki beberapa langkah : 1) studi pendahuluan dan mengumpulkan informasi dengan melakukan mencarian kebutuhan pembelajaran pada mata kuliah sepakbola. Selanjutnya pengumpulan informasi mengenai sumber potensi yang ada pada mahasiswa, dosen, dan sarana prasarana penunjang untuk diterapkanya model hybrid learning ini. 2) menyusun program pengembangan berdasarkan studi pendahuluan dan pengumpulan informasi melalui kajian teoritik, selanjutnya membuat rancangan desain hybrid learning : a) merumuskan garis besar tujuan dan program, b) membuat desain model pembelajaran hybrid learning pada mata kuliah sepakbola POR FKIP UMS, c) pengembangan produk dengan melakukan install LMS Schoology, membuat panduan penggunaan, membuat user, dan melakukan input materi perkuliahan sesuai rencana program semester (RPS) Sepakbola, d) uji empirik produk awal pada kelas uji diberi nama kelas $\mathrm{A}$, dengan melakukan evaluasi dan validasi produk awal hybrid learning oleh ahli media dan mahasiswa sebagai pengguna, e) melakukan revisi produk awal setelah evaluasi dan validasi dari ahli dan pengguna, f) uji empirik produk utama merupakan penilaian skala terbatas untuk mengetahui tingkat efektifitas produk pembelajaran hybrid learning pada mata kuliah sepakbola. g) revisi produk utama sebagai hasil pengembangan model produk tingkat operasional. Penelitian ini berskala kecil, maka langkah penelitian ini hanya dilakukan sampai langkah ke 7, untuk langkah 8, 9, 10 dilakukan dalam skala besar.

\section{Hasil dan Pembahasan}

\section{a. Analisis Instruksional}

Penelitian tahap pertama dalam langkahlangkahnya diperoleh hasil analisis instruksional. Tujuan instruksional akan menghasilkan identifikasi kemampuan berupa tugas-tugas pokok untuk mencapai tujuan. Dick and Carey (2001:61). Diperoleh analisis instruksional berupa kompetensi dan jabaran indikator, kompetensi dibuat sesuai analisis materi perkuliahan sepakbola yang dapat ditunjukkan 
dengan rencana program semester dan rencana program mingguan.

\section{b. Lingkup Pengembangan}

\section{Model Pembelajaran Hybrid Learning Sepakbola}

Tahap ini dihasilkan konten model pembelajaran hybrid learning untuk mata kuliah sepakbola. yaitu ; 1) nama mata kuliah, 2) topik seputar perkuliahan, 3) panduan penggunaan program, 4) kompetensi inti mata kuliah, 5) rancangan perkuliahan, 6) materi, dan 7) perkiraan waktu perkuliahan. Dalam diskripsi singkat program mengenai pokok bahasan sampai sub pokok bahasan disesuaikan dengan kurikulum yang tertuang pada rencana program semester sepakbola (RPS) sebagai berikut; a.
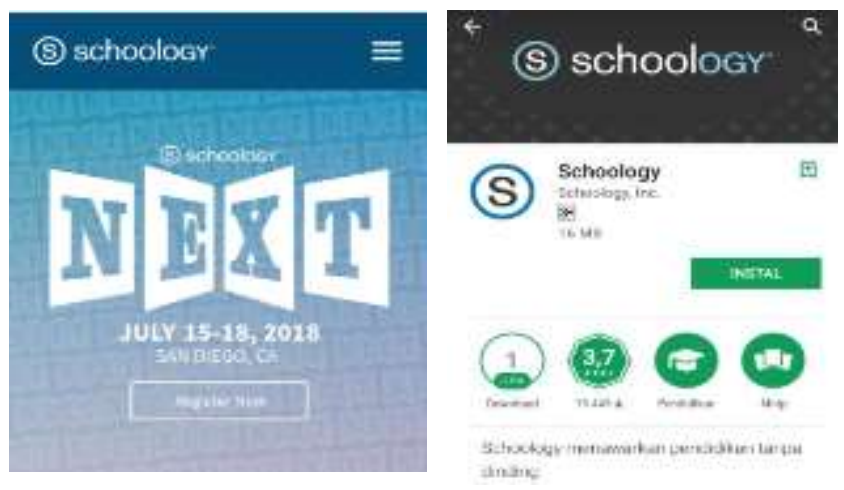

\section{Gambar 1. Tampilan Muka Guka instal Schoology Schoology di Web \\ Muka instal Schoology di Play Store}

sejarah perkembangan sepakbola, ketrampilan dasar bermain sepakbola, taktik dan strategi, peraturan dan perwasitan sepakbola, sitem pertandingan, dan penyelenggaraan pertandingan sepakbol. Untuk pengembangan strategi pembelajaranya berupa chatting/ posting, materi teks, file word/ power point (pdf/word), media video maupun gambar/ foto.

\section{c. Pengembangan Model}

Tahap ini menjelaskan model pengembangan pembelajaran hybrid learning sebagai berikut; 1) dosen melakukan regristrasi untuk menjadi anggota (member) pada e learning dengan Learning Management System (LMS) Schoology, setelah dosen mendapatkan user id dan password, dosen melakukan $\log$ in dan membuat kelas (courses) sepakbola, selanjutnya dosen menambahkan mahasiswa (member) dalam kelas sepakbola, setelah itu dosen merancang materi perkuliahan dan konten kelas sepakbola sesuai fasilitas yang disediakan pada e learning Schoology. Mahasiswa setelah regristrasi dan mendapatkan user id dan password, maka mahasiswa bergabung (joint) ke dalam kelas sepakbola setelah mendapatkan code akses dari dosen pengampu mata kuliah sepakbola. Setelah mahasiswa berhasil bergabung dalam kelas sepakbola, maka aktifitas pembelajaran dapat dimanfaatkan oleh mahasiswa sesuai dengan instruksi dari dosen pengampu, adapun aktifitas pembelajaran berupa chatting, download materi dan tugas, quiz, informasi, nilai evaluasi ujian. Kemudahan ini kemudian dikombinasikan dengan pembelajaran tatap muka di kelas dalam bentuk penguatan dan penguasaan ketrampilan dari materi dalam e learning Schoology.

\section{d. Instalasi Schoology}

Persiapan yang sudah direncanakan menggunakan domain dengan alamat http://www.schoology.com dalam tahap uji coba domain ini belum di digunakan secara resmi dalam keperluan kampus. Domain ini juga dapat di install dalam play store untuk pengguna handphone berbasis android. Berikut gambar tampilan muka shoology pada website dan play store ;

\section{e. Validasi Produk Pembelajaran}

Proses evaluasi produk awal yang dikembangkan dengan tujuan melihat beberapa aspek relevansi konten, fitur tampilan, dan keterlaksanaan produk (user frienldly) dengan melibatkan 1 orang ahli materi, dan 2 orang ahli media.

Tabel 1. Validasi Ahli Materi

\begin{tabular}{|c|c|c|c|}
\hline No & Aspek penilaian & Uji awal & Uji revisi \\
\hline 1 & Konten pembelajaran & 3,10 & 3,67 \\
\hline \multirow[t]{3}{*}{2} & $\begin{array}{l}\text { Kualitas } \\
\text { pembelajaran }\end{array}$ & 3,54 & 4,14 \\
\hline & Rata- rata & 3,32 & 3,91 \\
\hline & Kriteria & Cukup baik & Baik \\
\hline
\end{tabular}

Hasil validasi dari ahli materi tahap uji 
coba awal "cukup baik" dengan rata- rata 3,32 sedangkan untuk tahap uji coba setelah revisi meningkat dengan katagori "baik" rata- rata 3,91. Berikut gambar hasil validasi ahli materi ;

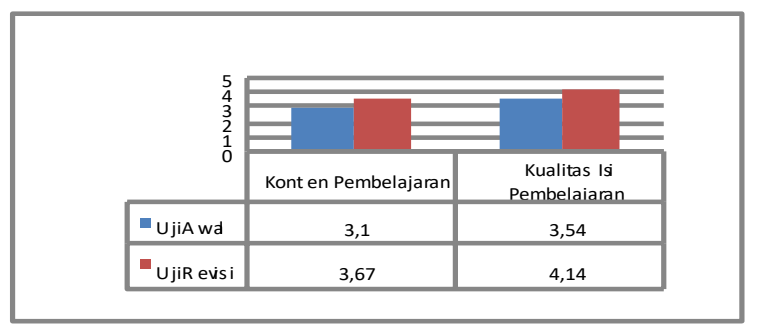

Gambar 3. Kualitas Produk Hasil Validasi Ahli Materi

Tabel 2. Validasi Ahli Media

\begin{tabular}{cclll}
\hline $\begin{array}{c}\text { No Aspek } \\
\text { penilaian }\end{array}$ & Ahli Media I & $\begin{array}{l}\text { Ahli } \\
\text { Media II }\end{array}$ & Rerata \\
\hline 1 & Program & 3,52 & 3,62 & 3,57 \\
2 & Tampilan & 3,78 & 3,75 & 377 \\
& & $\begin{array}{l}\text { Rata- rata } \\
\text { Kriteria }\end{array}$ & & $\begin{array}{l}\mathbf{3 , 6 7} \\
\text { Baik }\end{array}$ \\
\hline
\end{tabular}

Kualitas produk hasil validasi ahli media I dan ahli media II dari aspek pemrograman dengan nilai rata- rata 3,57. Sedangkan dari aspek tampilan memperoleh nilai 3,77. Rerata aspek yang dinilai dari kedua ahli 3,67 dengan katagori "baik". Berikut gambar kualitas produk hasil validasi ahli media ;

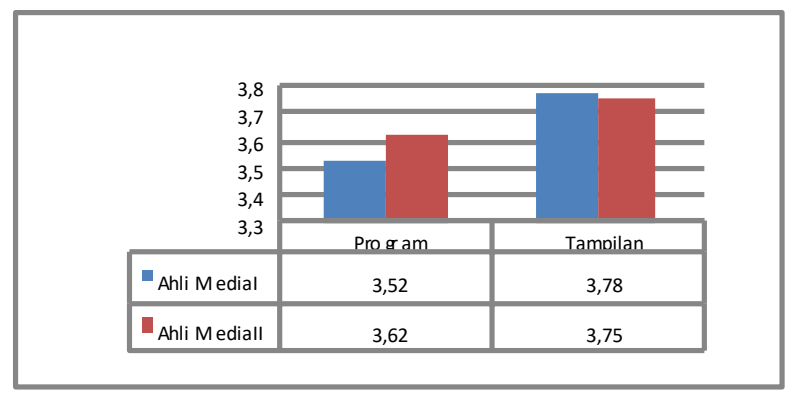

Gambar 4. Kualitas Produk Hasil Validasi Ahli Media

\section{f. Uji Efektifitas Produk Utama}

Dari uji efektifitas produk yang dikembangkan berupa tes formatif menggunakan instrument tes yang sama pada kedua kelas yaitu kelas eksperimen dan kelas kontrol. Setelah menggunakan media tingkat penguasaan materi terjadi peningkatan. Adapun hasil uji coba efektifitas produk utama sebagai berikut :
Tabel 3. Hasil Uji Efektifitas Produk Utama

\begin{tabular}{|c|c|c|}
\hline No Tes & $\begin{array}{l}\text { Jumlah } \\
\text { Mahasiswa }\end{array}$ & $\begin{array}{c}\text { Skor Rata- rata Skor } \\
\text { Mahasiswa }\end{array}$ \\
\hline Pre test & 204 & 6,8 \\
\hline Post test & 225,8 & 7,53 \\
\hline & Selisih skor & $\mathbf{0 , 7 3}$ \\
\hline
\end{tabular}

Dari hasil perhitungan rata- rata pre test dari 30 mahasiswa adalah 6,8 dengan jumlah total skor 204. Setelah menggunakan media pembelajaran hasil penguasaan materi meningkat menjadi 7,53 dengan total skor 225,8. Terdapat selisih point antara pre test dan post test sebesar 0,73 point, maka dapat disimpulkan bahwa terjadi peningkatan dalam penggunaan media pembelajaran berbasis hybrid learning pada mata kuliah sepakbola. Berikut gambar hasil uji produk utama ;

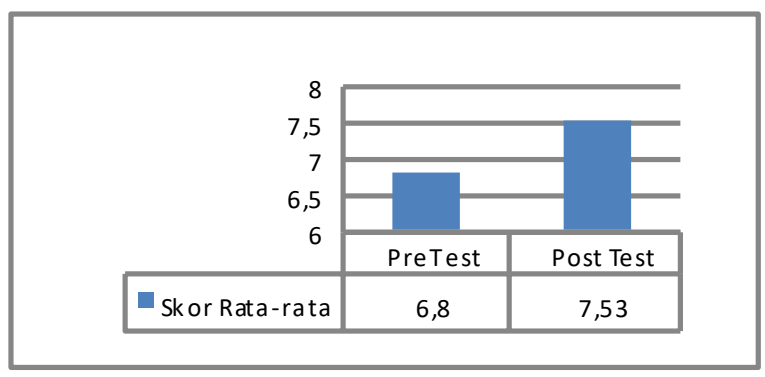

Gambar 5. Hasil Uji Efektifitas Produk

\section{Pembahasan}

\section{a. Pengembangan Media}

Kegiatan pengembangan pembelajaran hybrid learning diawali dengan analisis instruksional, lingkup pengembangan, model pengembangan hybrid learning dan instalasi LMS Schoology di Play Store. Hasil evaluasi produk awal, maka diperoleh hasil produk utama setelah dilakukan revisi oleh ahli materi, ahli media dan mahasiswa serta uji coba kelompok kecil.

\section{b. Karakteristik Media Pembelajaran yang dikembangkan}

Model hybrid learning dengan karakteristik : menggunakan e learning sebagai metode pembelajaran sepakbola dengan cara membukan website dan mendownload aplikasi di play store, fasilitas dalam model pengembangan berupa diskusi, chatting, add media mengirim 
link, upload file yang memudahkan dosen dan mahasiswa melakukan interaksi, dan setelah dikembangkan pembelajaran dengan hybrid learning memiliki kemenarikan tampilan dan kemudahan dalam penggunaan.

\section{c. Keunggulan Produk Hasil Pengembangan}

Produk hasil pengembangan memiliki keunggulan : 1) Konten materi sesuai dengan kurikulum yang diturunkan ke dalam rencana program semester (RPS) dan rencana program mingguan (RPM), 2) Materi yang diberikan sudah dalam bentuk softcopy sehingga memudahkan mahasiswa untuk mendownload dan mengedit sesuai kebutuhan Presentasi saat Pembelajaran Tatap Muka.3). Dosen dengan mudah dapat melakukan update materi sehingga materi kuliah tidak ketinggalan jaman. 4). Mahasiswa cendrung lebih mandiri saat melaksanakan pembelajaran.

\section{d. Keterbatasan Produk Hasil Pengembangan}

Terdapat

keterbatasan

dalam pengembangan pembelajaran hybrid learning ini, antara lain : 1) harus tersedia komputer ataupun handphone, 2) komputer dan handphone harus terkoneksi dengan jaringan internet untuk mengakses dan mendownload fitur di Schoology, 3) pembelajaran hybrid learning dapat dilakukan pada perguruan tinggi yang sudah tersedia sarana dan prasarana yang mendukung.

\section{e. Keterbatasan Penelitian}

Keterbatasan penelitian pengembangan ini adalah belum adanya uji efisiensi produk sehingga belum bisa diperkirakan lama waktu dan biaya diperlukan mendownload konten mata kuliah.

\section{Kesimpulan dan Saran}

\section{Kesimpulan}

1) Dari pengembangan pembelajaran ini, maka diperoleh hasil pengembangan hybrid learning yang sesuai untuk diterapkan pada mata kuliah sepakbola di Prodi Pendidikan Olahraga FKIP UMS. Penelitian pengembangan pembelajaran hybrid learning mampu mengubah pendekatan pembelajaran berpusat pada dosen menjadi berpusat pada mahasiswa. Kemandirian dan keaktifan mahasiswa menjadi bertambah dengan semakin leluasanya mahasiswa untuk berinteraksi dan memperoleh informasi melaui chatting, download materi, upload tugas. Dalam pengembangan pembelajaran hybrid learning sepakbola ini selain menggunakan pembelajaran e leaarning juga dilakukan pembelajran tatap muka sebagai implementasi materi praktik sepakbola.

2) Dengan pemanfaatan hybrid learning dalam mata kuliah sepakbola terjadi peningkatan prestasi belajar mahasiswa.

3) Adanya antusiasme mahasiswa dalam mengikuti mata kuliah sepakbola dengan model pembelajaran hybrid learning ini, terbukti dari tingkat partisipasi mahasiswa dalam mengerjakan tugas, mendownload materi, memberikan komentar dalam forum diskusi.

4) Adanya kemudahan dalam menggunakan model pembelajran ini karena dapat dilakukan dimanapun dan kapanpun.

\section{Saran}

1) Perlu adanya penerapan model pembelajaran hybrid learning ini pada mata kuliah yang lain dalam prodi pendidikan olahraga karena sangat membantu meningkatkan antusiasme dan hasil belajar mahasiswa.

2) Dosen harus melakukan inovasi- inovasi pembelajaran sesuai dengan perkembangan IPTEK.

3) Mahasiswa diharapkan dapat memanfaatkan perkembangan teknologi sebagai bentuk efektifitas pembelajaran.

4) Perlu adanya ahli materi dan ahli IT sebagai konsultan apabila terjadi ketidaksesuaian konten maupun terjadi gangguan jaringan.

5) Perlu sosialisasi dan petunjuk pengoprasian terlebih dahulu kepada dosen dan mahasiswa.

6) Mahasiswa dan dosen turut serta dalam pemanfaatan teknologi berbasis jaringan dan tetap melaksanakan perkuliahan tatap muka dengan menggunakan model pembelajaran hybrid learning. 


\section{Daftar Pustaka}

Djamarah, Syaiful B dan Zain, Aswan, 2002. Strategi Belajar Mengajar, Rineka Cipta Jakarta,

Emzir, 2010, Metodologi Penelitian Pedidikan, PT. Raja Grafindo Persada, 2010, Jakarta

Harjanto, 2006. Perencanaan Pengajaran, PT. Rineka Cipta, Jakarta,

Harun, Jamaluddin dan Baharuddin Aris, 2002. Mendesain pembelajaran Berbasis Web: Perspektif anak didik dalam Jurnal Teknodik Komunikasi dan Informasi Pendidikan, Jakarta

Hardjito, 2002. Internet untuk Pembelajaran dalam Jurnal Teknodik: No.10/VI/Teknodik/Oktober

Heru Suhartanto, "Survei 2009: "Mutu Situs eLearning Sekolah Indonesia Masih Sangat Minim", dalam Journal of Information Systems, Volume 6, Issues 1, April 2010.

Kadir, A., 2007 Pengenalan Sistim Informasi, Andi Offset.Yogyakarta.

Nasution, S, 2006. Metode Research (Penelitian Ilmiah), PT. Bumi Aksara,

Wahono, RS. 2006 Pengantar E-Learning dan Pengembangannya, Ilmu Komputer.com download tanggal 20 Februari 2018 